\title{
Sister chromatid exchange frequencies in patients with scleroderma and their relatives
}

\author{
R G PALMER, ${ }^{1}$ R S PEREIRA, ${ }^{1}$ C J DORE, ${ }^{2}$ AND A M DENMAN 1 \\ From the ${ }^{1}$ Connective Tissue Diseases Research Group and ${ }^{2}$ Division of Medical Statistics, Clinical Research \\ Centre, Harrow, Middlesex
}

SUMmARY Sister chromatid exchange (SCE) analysis is a sensitive measure of chromosome damage induced by many agents which damage DNA. These agents have been reported to be present in the serum of patients with scleroderma. Chromosome aberrations are thought to be more common in cells of these patients and their relatives than in cells of controls. We have observed that the SCE frequencies in blood lymphocytes of patients with scleroderma and their relatives do not differ from those of controls.

Key words: family study.

Blood lymphocytes of patients with scleroderma have been observed to show more chromosome aberrations than those of healthy individuals. ${ }^{1}$ Their family members may also have high numbers of chromosome abnormalities, albeit of a different type to those of the probands and normal controls. ${ }^{2}$ The reason for these abnormalities is unknown. They may be related to clastogenic factors, small molecules which can damage DNA and induce chromosome aberrations. ${ }^{3}$ Some workers predicted that chromosome damage in these patients would be manifest as raised sister chromatid exchange (SCE) frequencies ${ }^{4}$-SCE analysis is a very sensitive measure of chromosome damage induced by some DNA damaging agents. ${ }^{5}$ Three patients were subsequently found to have higher SCE frequencies than controls. ${ }^{4}$

We report our findings on spontaneous SCE frequencies in lymphocytes of patients with scleroderma and their relatives.

\section{Patients and methods}

PATIENTS

SCE frequencies have been determined in peripheral blood lymphocytes of 16 patients with scleroderma and 31 relatives of nine of these patients. Fifteen patients were female and one was male.

Accepted for publication 17 September 1985.

Correspondence to Dr R G Palmer, Connective Tissue Diseases Research Group, Clinical Research Centre, Watford Road, Harrow. Middlesex HA1 3UJ.
Their ages ranged from 18 to 73 years and all were Caucasian except for one West Indian female. Five were smokers, nine were non-smokers, and details of smoking habits were not available for two patients. Many were receiving no drug therapy and none had ever received cytotoxic treatment. All patients fulfilled the American Rheumatism Association (ARA) criteria for scleroderma, ${ }^{6}$ and for each one the presence or absence of proximal scleroderma, pitting of fingertips, pulmonary fibrosis, and sclerodactyly was determined. Twenty healthy individuals and 32 hospital inpatients or outpatients with diseases other than connective tissue diseases served as controls.

SCE ANALYSIS

SCEs were determined from metaphase spreads prepared from blood lymphocytes in whole blood cultures. Details of the technique used have already been published. ${ }^{7}$ SCEs were counted from 20 metaphases on coded samples.

\section{STATISTICAL ANALYSIS}

The patients and controls formed part of a large survey of SCE frequencies in 279 controls and patients with various connective tissue diseases. One hundred and ninety four of these individuals had never received cytotoxic drugs. The results for all 279 individuals have been used to establish the most appropriate transformation of the data: logarithms were taken of the original SCE readings +1 and for each individual the mean $\log (\mathrm{SCE}+1)$ was deter- 
mined. The mean and SD of the mean $\log (\mathrm{SCE}+1)$ for each group was calculated and the values for each group were compared by Student's $t$ test. The results for the 194 individuals not on cytotoxic drugs have been used to model the independent effects of type of connective tissue disease, age, sex, race, and smoking habits on SCEs: SCEs increase with age by $2 \%$ per decade; SCEs are not significantly affected by the sex of an individual; SCEs of West Indians do not differ from those of Caucasians; and the SCEs of smokers are approximately $5 \%$ higher than those of non-smokers of similar age. Therefore it has been possible in this report to adjust SCE data for these variates and factors. Specific data concerning the adjustments for all patients in the large survey are available ${ }^{8}$ and will be published elsewhere.

\section{Results}

An example of a metaphase demonstrating SCEs is shown in Fig. 1 and the log transformed SCE data for each group are summarised in Table 1. The SCE frequencies do not differ significantly between any of the groups. In particular, the SCEs of the scleroderma patients are not higher than those of the controls and the SCEs of the relatives of the scleroderma patients are not higher than those of the patients themselves. There were still no signifi-

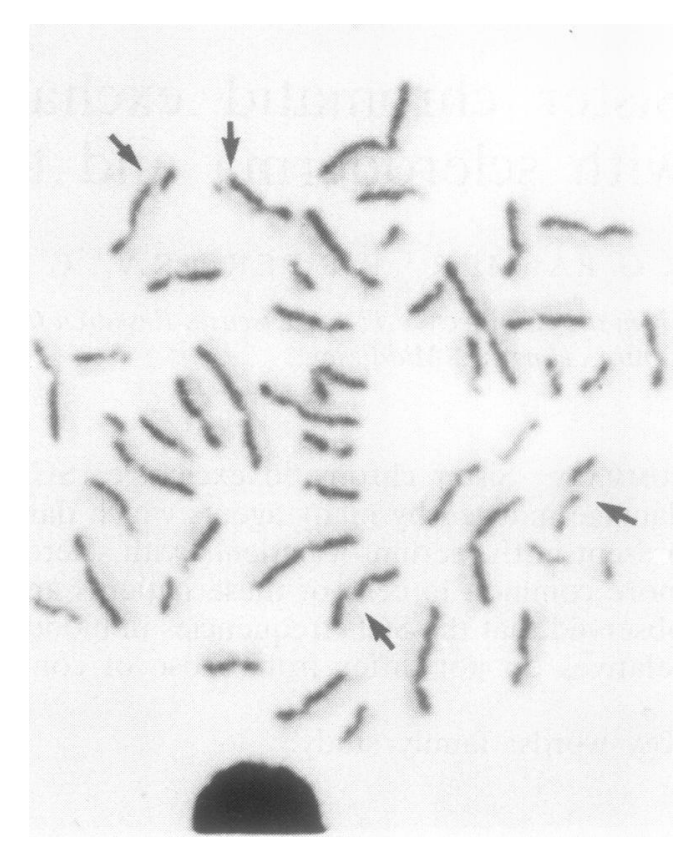

Fig. 1 Examples of SCEs. One chromatid of each chromosome is dark and its identical sister chromatid is pale. Exchange between sister chromatids (SCE) is easily visible (arrows).

Table 1 Log transformed SCE data for patients and controls

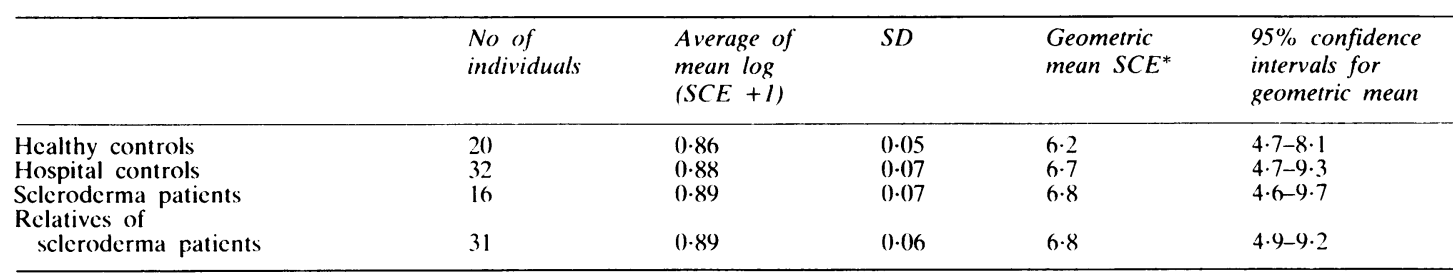

${ }^{*}$ Antilog (mean $\left.\log (\mathrm{SCE}+1)\right)-1$.

Table 2 Comparison of SCEs of scleroderma patients and their families

\begin{tabular}{|c|c|c|c|c|}
\hline \multicolumn{2}{|c|}{ Scleroderma patients } & \multicolumn{2}{|c|}{ Scleroderma relatives } & \multirow{2}{*}{$\begin{array}{l}\text { Mean log }(S C E+I) \text { of } \\
\text { patient minus } \\
\text { average mean log }(S C E \\
+I) \text { of relatives }\end{array}$} \\
\hline $\begin{array}{l}\text { Mean log } \\
(S C E+I)\end{array}$ & $\begin{array}{l}\text { No of } \\
\text { relatives }\end{array}$ & Relationships* & $\begin{array}{l}\text { Average mean } \\
\log (S C E+1)\end{array}$ & \\
\hline 0.80 & 3 & f,b,si & 0.91 & -0.11 \\
\hline $1 \cdot() 2$ & 5 & $h, f, m, s o, d$ & 0.94 & $0 \cdot 08$ \\
\hline 0.83 & 7 & f,m,b,b,b,si,si & 0.86 & -0.03 \\
\hline 0.98 & 5 & m,b,si,si,si & 0.86 & 0.12 \\
\hline$(0.86$ & 1 & b & 0.93 & -0.07 \\
\hline 0.89 & 6 & h.si,so,so,d,a & 0.90 & $-0 \cdot(01$ \\
\hline$(0.88$ & $i$ & so & 0.81 & 0.07 \\
\hline$(0.84$ & 2 & w,so & 0.89 & $-0 \cdot 05$ \\
\hline
\end{tabular}

${ }^{*} \mathrm{~h}=$ husband; $\mathrm{w}=$ wife; $\mathrm{f}=$ father: $\mathrm{m}=$ mother; $\mathrm{b}=$ brother; $\mathrm{s}=$ sister: $\mathrm{so}=\mathrm{son} ; \mathrm{d}=$ daughter; $a=a u n t$.

Paired $t$ test: mean difference $=-0 \cdot 01: \mathrm{SD}=0 \cdot 08 ; t_{\mathrm{x}}=-0 \cdot 32: \mathrm{p}=0.8$. 
cant differences between the groups when the data were adjusted for age, sex, smoking habits, and race of the members of each group (adjusted data not shown). In addition, there was no relationship between SCE frequencies and the presence of any single disease feature used in the ARA criteria or between SCE frequencies and the number of positive disease features possessed by an individual (data not shown).

The data were further analysed to determine if there was any consistent difference between SCE frequencies of an individual patient and the members of that patient's family. There was no evidence of a difference in mean SCEs between scleroderma patients and their families based on a paired within family comparison, either including or excluding husbands (Table 2). Variation between families was not significantly greater than variation within families $\left(F_{8.30}=1 \cdot 4, p=0 \cdot 3\right)$. The pooled estimate of standard deviation between individuals within families was $0 \cdot 06$, very similar to those for unrelated individuals given in Table 1.

\section{Discussion}

This study shows that SCE frequencies of patients with scleroderma and their relatives do not differ from those of either healthy or hospital controls. No differences emerged when allowances had been made for age, sex, smoking habits, and race of the individuals. Sherer et al reported that SCEs were higher in three patients with scleroderma than in controls who were matched for age, sex, and race. ${ }^{4}$ The smoking habits of the patients and controls should also have been considered because smokers have higher SCEs than non-smokers. ${ }^{910}$ The authors did not state whether these patients had had cytotoxic therapy in the past. This is important because chromosome damage induced by some cytotoxic drugs may be long lived and possibly permanent. $^{7}$

The variation of SCE frequencies within the families of our patients did not differ from the variation of SCE frequencies between families. Other workers have reported family studies of SCEs with different conclusions. Cohen et al observed that there is a greater variation of spontaneous SCEs between normal families than within families." Emerit et al have studied the chromosome aberrations of patients with scleroderma and those of their families. $^{2}$ There were some differences in the specific type of abnormalities present in the cells of the patients and their relatives, and both groups had a higher number of abnormalities than those of the normal controls. Our observations indicate that these chromosome abnormalities are not manifest as raised SCE frequencies and suggest that factors that can damage chromosomes to induce SCEs are unimportant in the aetiology of scleroderma.

We thank the UK Scleroderma Study Group for their assistance in obtaining blood samples from the relatives of patients with scleroderma and from some of the patients. We also thank Dr B M Ansell for blood samples from patients under her care.

\section{References}

1 Emerit I. Marteau R. Chromosome studies in 14 patients with disseminated sclerosis. Hum Genet 1971; 13: 25-33.

2 Emerit I. Housset E. Feingold J. Chromosomal breakage and scleroderma: studies in family members. J Lab Clin Med 1976: 88: 81-6.

3 Emerit I. Michelson A M. Chromosome instability in human and murine autoimmune disease: anticlastogenic effect of superoxide dismutase. Acta Physiol Scand 1980: 492: 59-65.

4 Sherer G K. Jackson B B. Leroy E C. Chromosome breakage and sister chromatid exchange frequencies in scleroderma. Arthritis Rheum 1981: 24: 1409-13.

5 Perry P. Evans H J. Cytological detection of mutagencarcinogen exposure by sister chromatid exchange. Nature 1975 258: $121-5$.

6 Masi A T. Rodnan G P. Medsger T A. Preliminary criteria for the classification of systemic sclerosis (scleroderma). Arthritis Rheum 1980): 23: 581-90.

7 Palmer R G. Dore C J. Denman A M. Chlorambucil-induced chromosome damage to human lymphocytes is dose-dependent and cumulative. Lancel 1984; i: 246-9.

8 Palmer R G. Sister chromatid exchange assessment of chromosome damage induced by cytotoxic drugs in patients with connective tissue diseases-are they at special risk? University of Oxford. 1984. 273 pp. (DM thesis.)

9 Soper K A. Stolley P D. Galloway S M, et al. Sister-chromatid exchange (SCE) report on control subjects in a study of occupationally exposed workers. Mutat Res 1984; 129: 77-8.

10 Vijayalaxmi. Evans $\mathrm{H} \mathrm{J}$. In vivo and in vitro effects of cigarette smoke on chromosomal damage and sister-chromatid exchange in human peripheral blood lymphocytes. Mutat Res 1982; 92: $321-32$.

11 Cohen M M. Martin A O. Ober C. Simpson S J. A family study of spontaneous sister chromatid exchange frequency. Am J Hum Genet 1982: 34: 294-306. 